AIAA 80-1872R

Effect of Propeller on Engine Cooling System Drag and Performance

J. Katz, V. R. Corsiglia, P. R. Barlow

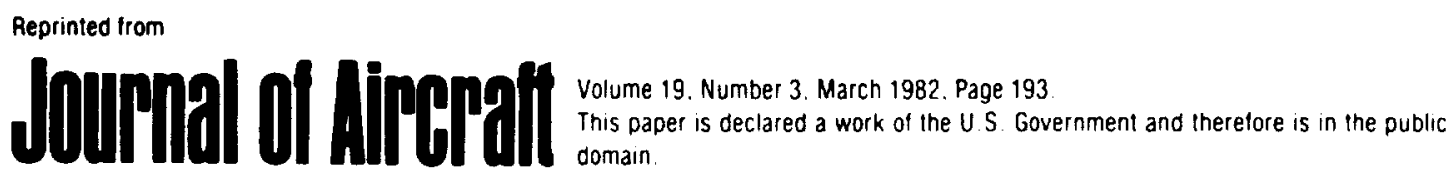




\title{
NASATM $-80-$ \\ 208075 \\ Effect of Propeller on Engine Cooling System Drag and Performance
}

\author{
Joseph Katz, * Victor R. Corsiglia, $\uparrow$ and Philip R. Barlow $\ddagger$ \\ NASA Ames Research Center, Moffett Field, Calif.
}

\begin{abstract}
The pressure recovery of incoming cooling air and the drag associated with engine cooling of a typical general aviation twin-engine aircraft was investigated experimentally. The semispan model was mounted vertically in the $40 \times 80$-Foot Wind Tunnel at Ames Research Center. The propeller was driven by an electric motor to provide thrust with low vibration levels for the cold-flow configuration. It was found that the propeller slip-stream reduces the frontal air spillage around the blunt nacelle shape. Consequently, this slip-stream effect promotes flow reattachment at the rear section of the engine nacelle and improves inlet pressure recovery. These effects are most pronounced at high angles of attack; that is, climb condition. For the cruise condition those improvements were more moderate.
\end{abstract}

\section{Nomenclature}

$A_{i} \quad=$ cooling air inlet area

$A_{\infty} \quad=$ upstream cooling airstream tube area

$C_{D} \quad=$ drag coefficient

$C_{P} \quad$ = propeller power coefficient $=P / \rho_{\infty} n^{3} D^{5}$

$C_{p_{u}} \quad=$ upper plenum total pressure coefficient

$C_{T} \quad$ = propeller thrust coefficient $=T / \rho_{\infty} n^{2} D^{4}$

$D T \quad=$ propeller diameter [193 cm (76 in.)]

$D_{\text {scale }}=$ measured drag component by the tunnel scale system

$J \quad=$ propeller advance ratio $=V_{\infty} / n D$

$n \quad=$ revolutions per second

$P \quad=$ propeller power

$p_{101} \quad=$ total pressure

$p_{\infty} \quad=$ freestream static pressure

$q_{\infty} \quad=$ freestream dynamic pressure $=1 / 2 \rho_{\infty} V_{\infty}^{2}$

$S=$ semispan model wing area $\left[8.6 \mathrm{~m}^{2}\left(92.6 \mathrm{ft}^{2}\right)\right]$

$T \quad=$ propeller thrust

$v_{\infty} \quad=$ freestream airspeed

$\dot{W} \quad=$ cooling air mass-flow rate

$\dot{W}_{c} \quad=$ required cooling air mass-flow rate $[1.4 \mathrm{~kg} / \mathrm{s}(3$ [b/s)]

$\alpha \quad=$ angle of attack

$\beta_{0.79}=$ propeller pitch angle

$\delta_{c f}=$ cowl flap deflection

$\rho_{\infty} \quad=$ freesiream air density

\section{Introduction}

$\mathbf{T}$ HE cooling system design of general aviation piston engine installations has recently received increased attention as fuel efficiency has become a more important factor in aircraft development. As a result, engine installation research, originally directed at solving powerplant cooling problems, is now concerned with nacelle drag reduction as

Presented as Paper 80-1872 at the AIAA Aircraft Systems and Technology Meeting, Anaheim, Calif., Aug. 4-6, 1980; submitted Sept. 12, 1980; revision received July 6, 1981. This paper is declared a work of the U.S. Government and therefore is in the public domain.

- NRC Associale. Present address: Department of Mechanical Engineering, Technion, Haifa, Israel

†Aerospace Engineer. Member AIAA.

†Aerospace Engineer. well. Recent studies of this so-called "cooling drag" are cited in Refs. 1-5. These studies differ from the studies of the World War II era and before in that most general aviation aircraft now use horizontally opposed engine configurations, whereas most pre-World War II aircraft used air-cooled radials or in-line layouts.

Monts' has provided the designer with a list of engine installation data and a procedure for sizing the components of a cooling system. The reshaping of cooling air inlets to provide less pressure head loss was studied by Miley et al. ${ }^{2.3}$ They were successful in increasing inlet pressure recovery; however, nacelle drag data were not reported.

Extensive studies of opposed piston engine nacelle drag were performed in the $40 \times 80$-Foot Wind Tunnel at Ames Research Center. These studies ${ }^{4.3}$ were carried out without the propeller in order to measure mass-flow rates and nacelle drag accurately. In the work reported herein, an electric-motordriven propeller was added to the nacelle; this made it possible to study the effect of the propeller slip-stream on the pressure recovery of the cooling air inlets and on the nacelle drag. The major advantage of using an electric motor for this purpose was that cold-flow measurements comparable to the propeller-off data could be performed. Moreover, the lowvibration torque and thrust of an electric-motor-driven propeller was simpler to measure, which resulted in a more accurate measurement of nacelle drag.

\section{Experimental Apparatus}

The general layout of the vertically mounted semispan model is seen in Fig. 1. The end plate was used to separate the model from the tunnel boundary layer and to serve as a reflection plane. Forces were measured through a shielded strut that passed through the end plane to the tunnel scales below the floor. Three inlet inserts (Fig. 2) served to decrease inlet area when placed into the production inlet. The internal arrangement of the nacelle and a sketch of an incoming streamtube are shown in Fig. 3. The upstream cross-section area of the streamtube is $A_{\infty}$; after the external diffusion, the cooling airstream enters into the upper plenum via the inlet of cross section $A_{i}\left(A_{\infty}<A_{i}\right)$. At the upper plenum the pressure recovery is measured by eight total pressure (K:el) probes and four static holes in the rear corner of the plenum. 


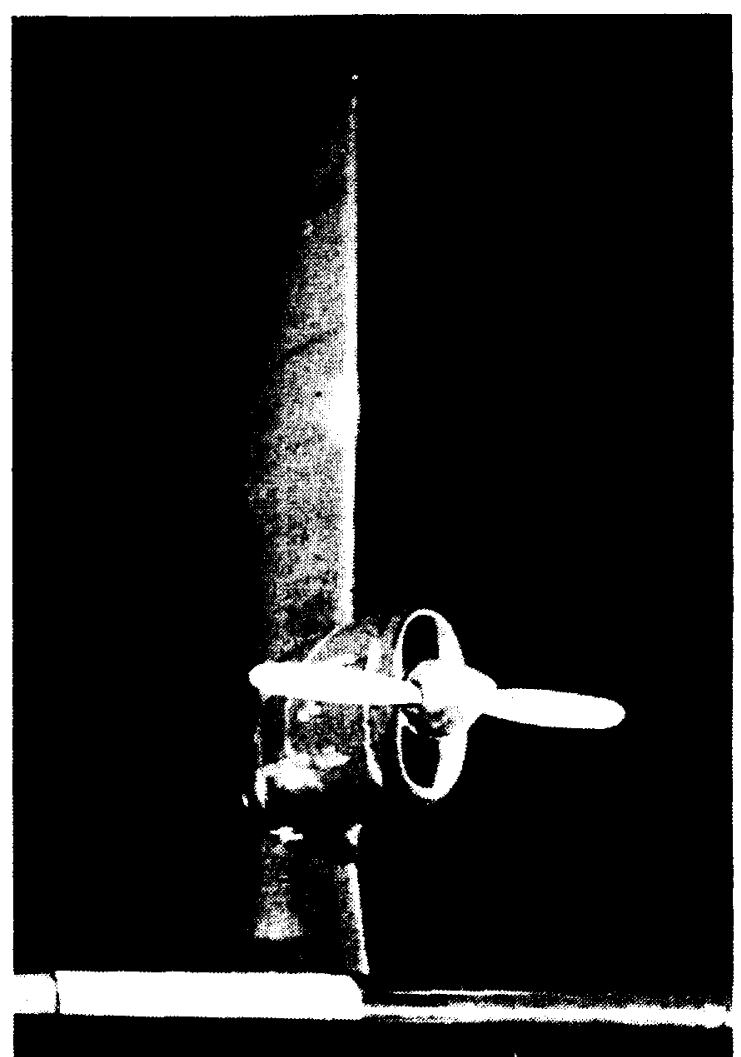

Fig. 1 Cooling-drag model in $40 \times 80-F o 01$ Wind Tunnel.

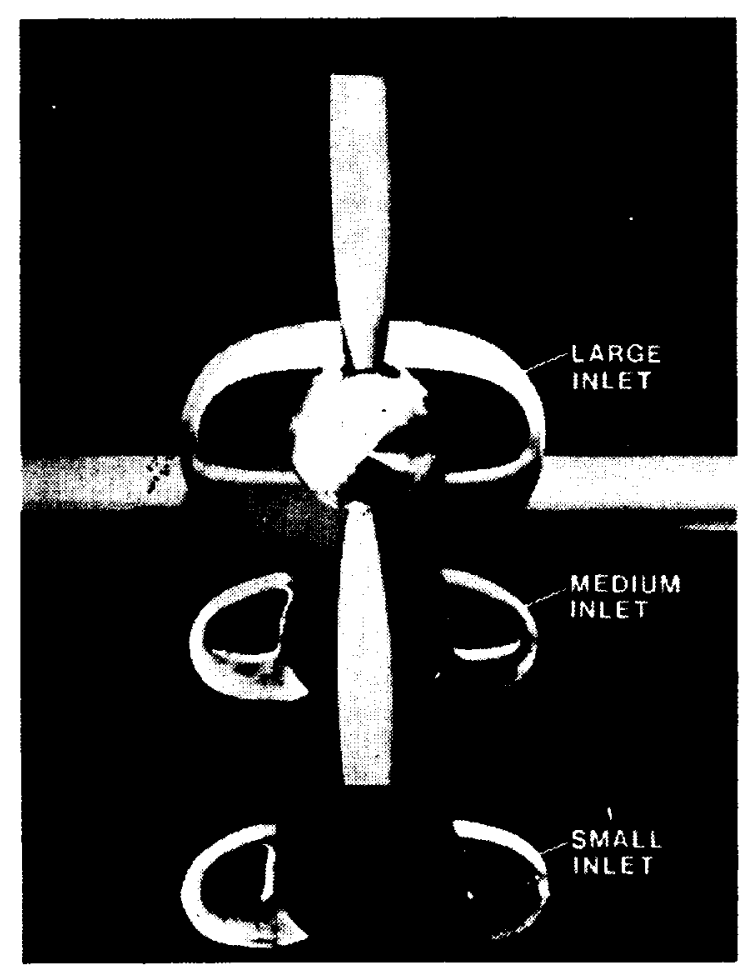

Fig. 2 Interchangeable inlets to reduce inlet size. Production inlet area: large, $690 \mathrm{~cm}^{2}\left(107\right.$ in. $\left.^{2}\right)$; medium, $393 \mathrm{~cm}^{2}$ (61 in. $\left.{ }^{2}\right)$; small, $265 \mathrm{~cm}^{2}$ (41 in. ${ }^{2}$ ).
The pressure recovery reported was the highest value measured; however, differences between the sensors were small (less than $0.05 q_{\infty}$ ). The cooling air then flowed through an adjustable orifice plate to the lower plenum. The size of the orifice opening was used to simulate various engine baffle configurations and served to vary the mass-flow rate through the cooling channel. The total pressure in the lower plenum was measured in a similar manner by four Kiel probes and four static holes; a rake of four Kiel probes measured the total head at the exit downstream of a cowl flap, which was also used to control the flow rate.

The electric motor [maximum output: $186 \mathrm{~kW}(250 \mathrm{hp})$ at $3600 \mathrm{rpm}$ ] was connected to the propeller through a torquemeter which was able to record shaft torque and propeller thrust simultaneously. Incoming signals were filtered with a 10- $\mathrm{Hz}$ low-pass filter before being recorded. The accuracy of drag-thrust data was of the order of $1 \%$; the lift accuracy was one order of magnitude better.

\section{Results}

Propeller Calibration

The objective of the study reported here was to investigate the parametric behavior of inlet pressure recovery and nacelle drag, relative to propeller-off measurements. ${ }^{4.5}$ As a first step the propeller was calibrated for torque and thrust as a function of advance ratio $J$ and blade-pitch angle $\beta_{0.7 y}$. The results of these tests along with a comparison with a propeller theory and a description of a spinner correction are contained in Ref. 6 . Figure 4 shows thrust coefficient vs advance ratio for various blade-pitch angles. These results are shown to be in agreement with the values obtained using the wind-tunnel scales and setting the model at 0 deg angle of attack. Table 1 shows the propeller operating conditions selected to be

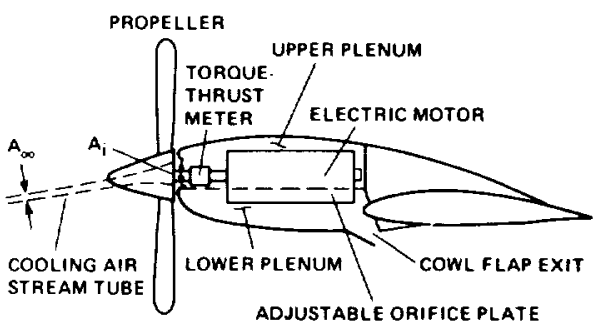

Fig. 3 Schematic of nacelle.

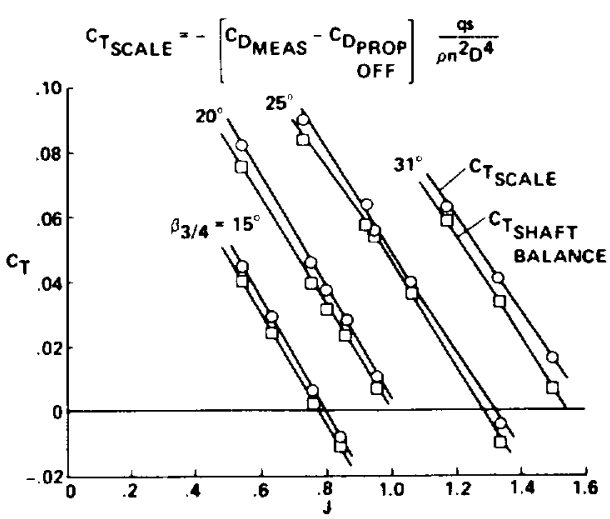

Fig. 4 Comparison of thrust measured on wind-tunnel scales with corresponding values measured on shaft balance. 
Table 1 Test conditions for climb and cruise configurations

\begin{tabular}{|c|c|c|c|c|c|c|c|c|c|c|}
\hline & Propeller & $\begin{array}{c}q . \\
\mathrm{cm} \mathrm{H} \mathrm{H}_{2} \mathrm{O} \\
\left(\mathrm{lb} / \mathrm{ft}^{2}\right)\end{array}$ & $\begin{array}{c}V_{\infty}, \\
\mathrm{m} / \mathrm{s} \\
(\mathrm{ft} / \mathrm{s})\end{array}$ & $\begin{array}{l}\alpha, \\
d e g\end{array}$ & $\begin{array}{l}\delta_{c f} \\
\text { deg }\end{array}$ & $\begin{array}{c}\beta_{0.75} \\
\text { deg }\end{array}$ & rpm & hp & $C_{T}=\frac{T}{\rho_{\infty} n^{2} D^{4}}$ & $J=\frac{V_{\infty}}{n D}$ \\
\hline \multirow[t]{2}{*}{ Climb } & on & $13.1(26)$ & $47(155)$ & 8 & 30 & 19 & 2450 & 180 & 0.063 & 0.58 \\
\hline & off & $15.1(30)$ & $50(166)$ & 8 & 30 & $\cdots$ & $\ldots$ & $\cdots$ & $\cdots$ & $\cdots$ \\
\hline \multirow[t]{2}{*}{ Cruise } & on & $40.3(80)$ & $84(272)$ & 2.3 & 0 & 25 & 2450 & 150 & 0.039 & 1.06 \\
\hline & off & $40.3(80)$ & $84(272)$ & 2.3 & 0 & $\ldots$ & $\ldots$ & $\ldots$ & $\ldots$ & $\ldots$ \\
\hline
\end{tabular}

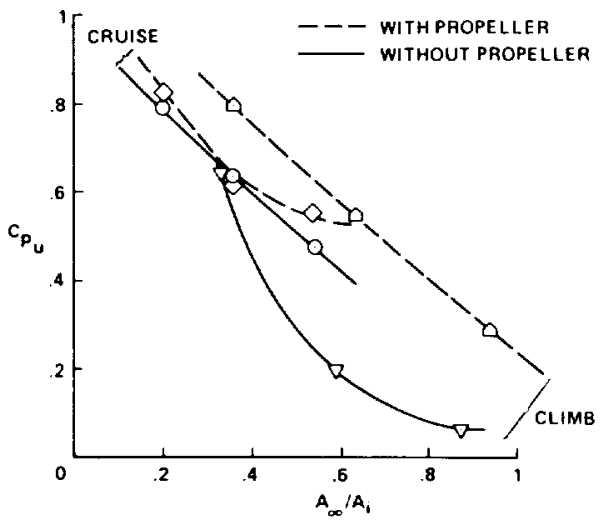

Fig. 5 Effect of propeller on inlet pressure recovery.

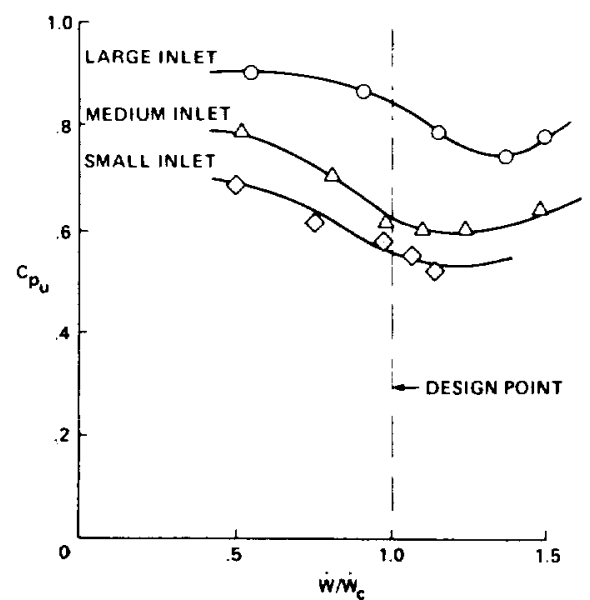

Fig. 6 Inlet pressure recovery vs cooling air mass-flow rale: cruise, with propeller.

representative of a cruise and a climb condition. These conditions were those used in the present study.

\section{Variation of Inlet Area}

The effect of the propeller slip-stream on nacelle drag and inlet pressure recovery was investigated and compared with the propeller-off data reported in Ref. 5 . The upper plenum pressure recovery $C_{p_{u}}$ as a function of inlet area ratio $A_{\infty} / A_{i}$, where $A_{\infty}$ is the incoming flow cross-section area ahead of the model (Fig. 3 ) and $A_{i}$ is the inlet area, is given in Fig. 5. Here the pressure coefficient is defined as

$$
C_{p_{u}}=\left(p_{101}-p_{\infty}\right) / q_{\infty}
$$

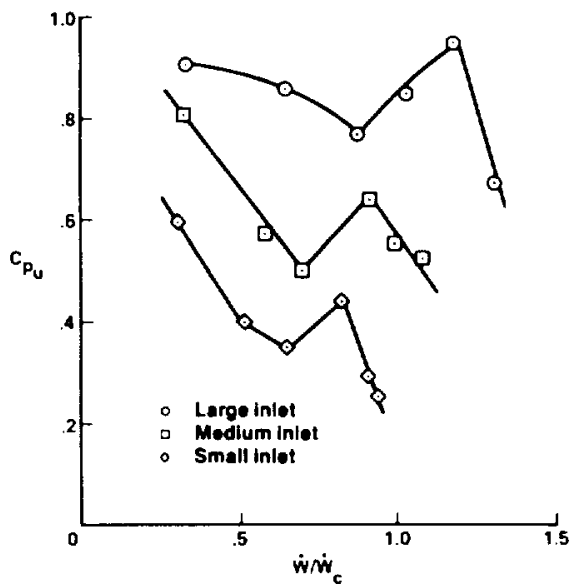

Fig. 7 Inlet pressure recovery vs cooling air mass-flow rate: climb. with propeller.

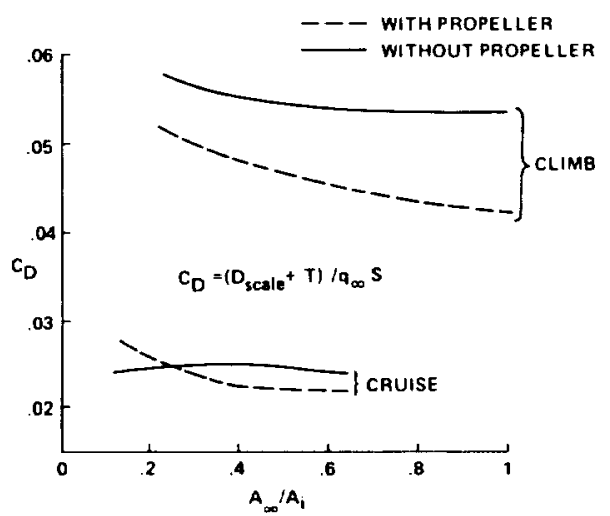

Fig. 8 Effect of propeller on semispan nacelle-wing drag.

These data were obtained for both the cruise and climb conditions that are given in Table 1 .

The measured pressure recoveries presented in Fig. 5 are in agreement with the results obtained by Miley et al. ${ }^{2.3}$ for inlets of area ratio 0.3 and 0.6 . Because their inlet configurations had improved internal diffuser contours, however, the small inlets $\left(A_{\infty} / A_{i}=0.6\right)$ in their test gave a slightly improved pressure recovery of $C_{\rho_{u}}=0.6-0.7$.

The effect of the propeller on inlet pressure recovery at cruise is small. This agrees with the observation of Miley et al. ${ }^{2,3}$ of a $5 \%$ increase in inlet total head because of propeller slip-stream. For the climb condition and the lowest value of $A_{\infty} / A_{i}$ (largest inlet area), the effect of the propeller is to add about $20 \%$ to the upper plenum pressure. This is, again, in close agreement with the results of Miley et al. ${ }^{2.3}$ At higher 


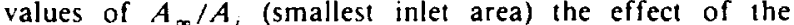
propeller is much greater. Nevertheless, even with the propeller installed, there is a substantial decrease in inlet pressure recovery $C_{p_{u}}$ as $A_{\infty} / A_{\text {, increases. This indicates that }}$ even with the propeller slip-stream present, there is still considerable internal flow separation in the upper plenum. This nonlinear behavior is demonstrated in Figs. 6 and 7, in which the upper plenum pressure recovery $C_{p}$ is plotted vs mass-flow rate $\dot{W}$. At the cruise condition, a slight increase in pressure recovery is measured for the higher flow rates. This might possibly be an indication of reattachment in the internal flow. The basic trend of higher pressure recovery for the larger inlets is maintained with the propeller on for the cooling air flow rates that were tested.

The drag coefficient $C_{D}$ vs area ratio $A_{\infty} / A$, is plotted in Fig. 8. The $C_{D}$ values shown in Fig. 8 and throughout the paper have been corrected for shaft thrust by adding the measured shaft thrust $T$ to the measured scale data $D_{\text {scale }}$ for the wing propeller combination

$$
C_{D}=\left(D_{\text {scale }}+T\right) / q_{\infty} S
$$

Therefore the $C_{D}$ values reflect the influence of the propeller slip-stream on the wing nacelle, but do not include the shaft thrust. To interpret these results, a schematic flowfield around the wing nacelle is drawn in Fig. 9. The drawing is based on tuft observations in the wind tunnel which indicated that the airstream spillage, that is, thickened boundary layer and high local velocities at the nacelle blunt front end, causes flow separation at the aft section of the wing-nacelle fairing

The drag results in Fig. 8 can be interpreted in terms of this flowfield sketch. In the cruise condition, the angle of attack is low and the aft flow separation is small. Therefore the favorable effect of the propeller slip-stream reduces the flow separation, but the resulting drag reduction is offset by the increased skin friction. Consequently, the effect of the propeller on drag is small. In the climb configuration with the propeller off, however, the aft flow separation has been increased. The net effect, then, of the propeller is to substantially reduce the drag by suppressing the flow separation on the aft nacelle.

A related study was conducted by Becker, ${ }^{7}$ who measured the drag of streamlined bodies with frontal inlets. His results showed, however, that the smaller inlet had lower drag even without the propeller, since the aft section of his model was streamlined.

\section{Effect of Power}

The effect on drag of increasing power setting is plotted vs mass-flow rate, for the large inlet area, in Fig. 10. It can be seen that the effect of the power is the same as that shown in

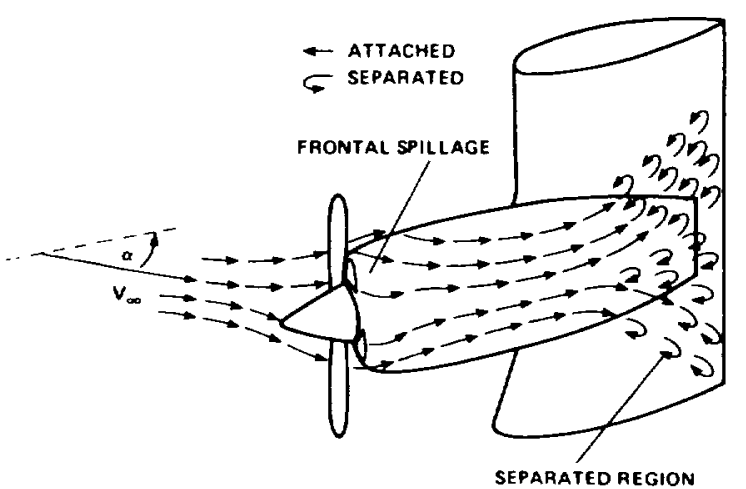

Fig. 9 Schematic description of flowfield about nacelle (as obtained by tuft s(udies).
Fig. 8. At cruise the drag increases as power is increased, and at climb the drag decreases because of the suppression of flow separation at the aft portion of the nacelle. At lower flow rates $\left(\dot{W} / \dot{W}_{c}<0.8\right)$, however, the effect of the frontal spillage is large enough that drag is not reduced because of thrust until the thrust becomes greater.

The increase in the drag coefficient as the cooling air flow rate is increased (with the propeller of $)$ is presented in Fig. 10 . When the propeller was added, however, a reduction in drag was observed for increased mass-flow rates. It seems that for the larger inflows, the flow disturbance at the propeller root and in the front of the nacelle is reduced, resulting in a thinner boundary layer and lower drag.
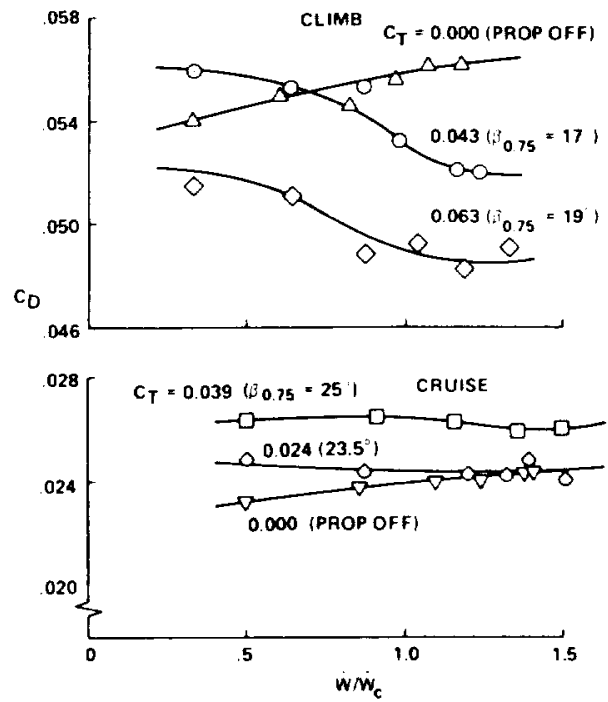

Fig. 10 Effect of propeller power on wing-nacelle drag for production configuration.

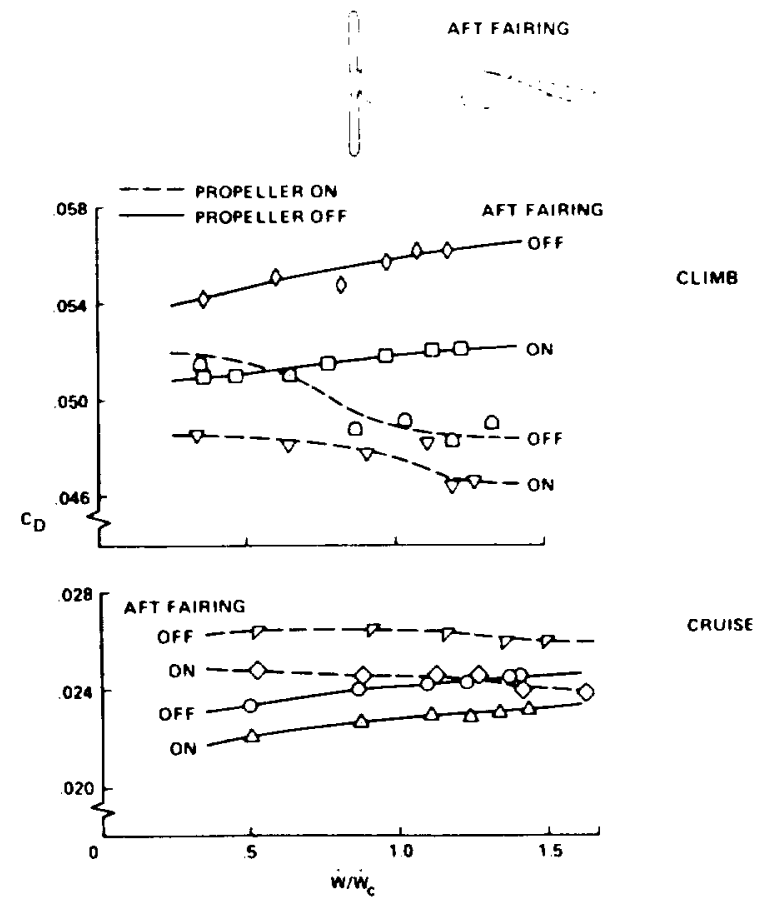

Fig. 11 Effect of aft fairing on wing-nacelle drag for production configuration. 


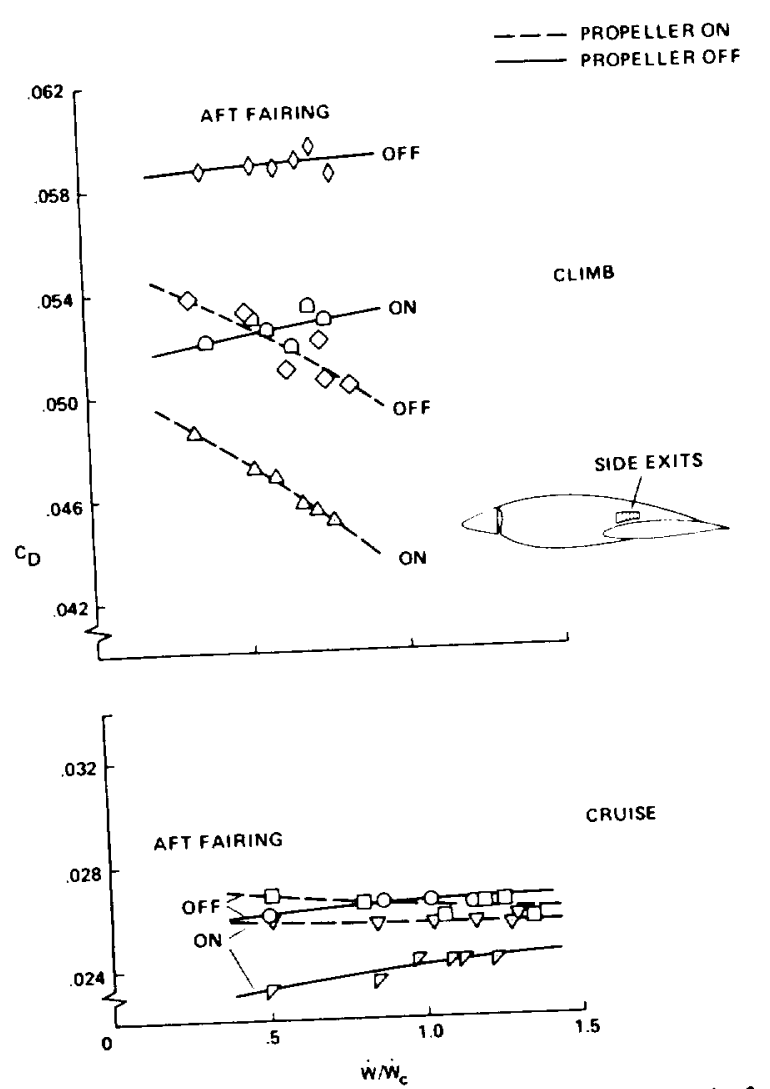

Fig. 12 Effect of aft fairing on wing-nacelle drag (using side exits for cooling air).

\section{Variation of Nacelle Aft Section}

Figures 8-10 illustrate the strong dependence of nacelle drag the amount of flow separation behind the nacelle. To reduce that effect, an aft fairing (shown in Fig. 11) was tested educe that esults in Fig. 11 with various nacelle configurations. show that for both propeller-off (solid effect of the aft faing is (dashed lines) the drag reduction this reduction is of the same present. At the cruise con case, and at the climb condition the order as the propeller-ofiction is smaller (by $201040 \%$ ) than the propeller-on drag redug reduction, especially for the higher flow rates $(\dot{W})$. This is because the propeller has suppressed the rates $(W)$. This is bection with the aft fairing of as discussed above, fow the aft fairing is therefore less.

Side Exits

Similar behavior was observed when the aft fairing was added to nacelle configuration that uses side ports for the exits of the cooling air. For this configuration the cowl flap exit was sealed, as shown in Fig. 12. The results of Ref. 5 show that this particular side exit configuration increased flow separation over the rear part of the nacelle and thereby increased the drag. In the presence of the propeller slipstream, however, the drag is not only lower (generally), but also continues to decrease with flow rate; this is in contrast with the propeller-off configuration, for which the drag slightly increased with flow rates. When comparing Figs. 11 and 12 it is concluded that at cruise the side exiting configuration has slightly higher drag than the standard cow! exit. But for the powered climb condition the absence of the cowl flap makes the side exits competitive, especially with the aft fairing on.

\section{Conclusions}

The addition of a propeller to a wing-nacelle configuration educes the amount of flow separation over the aft part of the nacelle and at the inlet of the cooling air flow. This leads to a reduction in the configuration drag when the cooling air massflow rate is increased, since inlet spillage is reduced. When the inlet area was reduced, the drag decreased, unlike the propeller-off case in which the nacelle drag continued to be almost unaffected as the inlet area was reduced. These effects are more pronounced in the climb condition than at cruise. The inlet pressure recovery for the cruise condition improves as much as 5\% because of the slip-stream effect, while at climb this improvement is of the order of $20 \%$ for the production (large) inlet and even more for smaller inlets. These improvements are partially a result of propeller slip. Theam related pressure rise, but the major effect is the reduction in the amount of flow separation inside the inlet at the higher angles of attack.

\section{References}

'Monts, F., "The Development of Reciprocating Engine In'Mata General Aviation Aircraft," SAE Paper 73-0325. April 1973.

Miley, S.J. Cross, E J. Jr., and Owens, J.K., “An Investigation Miley, S.J., Cross, E.J. Jr., and Owerizontally Opposed Engine of the Aerodynamis $77-0467$. March-April 1977

Installation," SAE Paper 77-0467, Mareh April D.L., and Owens, J.K.,

${ }^{3}$ Miley, S.J., Cross, E.J. Jr., Lawrence, Dircraft Engine In"Aerodynamics of Horizontally Opposed

stallations," AIAA Paper 77-1249, April 1977. A. "Full-Scale Wind

${ }^{4}$ Corsiglia, V.R., Katz, J., and Kroeger, R.A., " Journol of Air. Tunnel Study of Nacelle Shape on Cooling

craft, Vol. 18, No. 2, Feb. 1981, pp. 82-88. P R "Study of Cooling

Katz, J., Corsiglia, V.R., and Barlow, P.R., 'Study of Cooling Air Inlet and Exit Geometries for Horizontally

Aircraft Engines," AlAA Paper 80-1242, June 1980. J, "Full-Scale

Garlow, P.R., Corsiglia, V.R., and Katz, J., Small TwinAerodynamic Characteristics of a Propeller Installed on 1981.

Engine Aircraft Wing Panel," NASA TM 81285 , May

"Becker, V.J., "Wind Tunnel Tests of Air Inlet and Outle Openi 1940. 